\title{
PENGGUNAAN KOMPOS BAGASE UNTUK MENGOPTIMALKAN PRODUKSI TANAMAN TERUNG (Solanum melongena $\mathrm{L}$.)
}

\author{
Risa Selfiani ${ }^{1}$, Darmansyah ${ }^{2}$ \\ Program Studi Teknologi Produksi Hortikultura, Jurusan Budidaya Tanaman Pangan \\ Politeknik Pertanian Negeri Payakumbuh, Tanjung Pati \\ *Email: Risaselfiani30@gmail.com
}

\begin{abstract}
Eggplant (Solanum melongena L.) is a plant species that is known as the fruit and vegetables grown for use as a food ingredient. Eggplant fruit is the fruit of a true single. Bagase compost is compost that comes from bagasse or the rest of the sugar mill. Bagase own compost organic matter content of about $90 \%, N$ content of $0,3 \%, 0,02 \% \mathrm{P}_{2} \mathrm{O}_{5}, \mathrm{~K}_{2} \mathrm{O} 0,14 \%, \mathrm{Ca} 0,06 \%$ and $0,04 \% \mathrm{Mg}$. The purpose of research is compost bagase on the cultivation of eggplant to reduce the use of chemical fertilizers and optimize plant production eggplant, farming systems semi-organic environmentally sustainable and analyze the feasibility of cultivation of eggplant with market potential in Payakumbuh and the district of Lima Puluh Kota. Independent business projects implemented during the four months from September to December 2015 and conducted experiments State Agricultural Polytechnic Payakumbuh with total area of $300 \mathrm{~m}^{2}$. Eggplant crop production on the independent business projects with the use of compost bagase treatment that is $575 \mathrm{Kg} / 300 \mathrm{~m}^{2}$, a profit of Rp. 835.310 , the profitability of $92 \%$ and RC Ratio of 1,92 .
\end{abstract}

Keywords: Compost bagase, eggplant,sugar cane bagase, district of Lima Puluh Kota, profit

\section{INTISARI}

Terung (Solanum melongena L.) merupakan jenis tumbuhan yang di kenal sebagai sayuran buah dan ditanam untuk dimanfaatkan sebagai bahan makanan. Tanaman ini termasuk salah satu kelompok tanaman yang menghasilkan biji Kompos bagase adalah kompos yang berasal dari ampas tebu atau sisa penggilingan

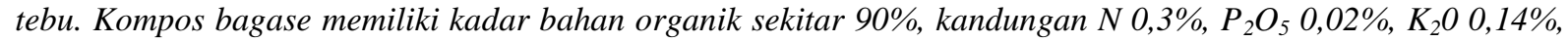
Ca $0,06 \%$ dan $\mathrm{Mg}$ 0,04\%. Tujuan pelaksanaan penelitian adalah penggunaan kompos bagase pada budidaya tanaman terung untuk mengurangi penggunaan pupuk kimia dan mengoptimalkan produksi tanaman terung, menerapkan sistem pertanian semi-organik yang berwawasan lingkungan dan berkelanjutan dan menganalisa kelayakan usaha budidaya terung dengan potensi pasar di Payakumbuh dan Kabupaten Lima Puluh Kota. Proyek usaha mandiri dilaksanakan selama 4 bulan yakni dari September sampai Desember 2015 dan dilaksanakan dikebun percobaan Politeknik Pertanian Negeri Payakumbuh dengan luas lahan $300 \mathrm{~m}^{2}$. Produksi tanaman terung pada proyek usaha mandiri dengan perlakuan penggunaan kompos bagase yaitu $575 \mathrm{Kg} / 300$ $m^{2}$, keuntungan Rp. 835.310, profitabilitas $92 \%$ dan RC Ratio sebesar 1,92.

Kata kunci : Kompos bagase, terung, ampas tebu, ampas tebu, kabupaten Lima Puluh Kota, keuntungan

\section{PENDAHULUAN}

Terung (Solanum melongena L.) merupakan jenis tumbuhan yang di kenal sebagai sayuran buah dan ditanam untuk dimanfaatkan sebagai bahan makanan. Terung merupakan tanaman asli daerah tropis yang cukup dikenal di Indonesia. Tanaman ini diduga berasal dari Benua Asia, terutama India dan Birma. Sebagai salah satu sayuran pribumi, buah terung hampir selalu ditemukan di pasar atau di pasar tradisional dengan harga yang cukup terjangkau oleh masyarakat. Akhir-akhir ini bisnis terung memberikan peluang pasar yang cukup baik terutama untuk memenuhi permintaan pasar dalam negeri. Beberapa varietas terung lokal seperti terung ungu yang belakangan ini telah berhasil menembus pasar luar negeri (Soetasad dan Muryanti, 1996).

Terung merupakan jenis sayuran yang sangat populer dan disukai banyak orang. Selain karena rasanya yang memang enak, kandungan gizinya pun cukup memadai. Bagian tanaman terung yang dimanfaatkan untuk hidangan masakan adalah buahnya. Kulit buahnya liat tetapi bila digigit terasa renyah. Bila dimasak terung akan menjadi layu dan menjadi lebih enak dimakan. Terung banyak dikonsumsi dengan memasaknya menjadi sayur, digoreng atau dimakan mentah sebagai lalapan (Soetasad 
dan Muryanti, 1996). Semakin beragamnya selera masyarakat terhadap terung, bentuknya juga semakin beragam. Namun ciri fisik terung tidak jauh berbeda dari karakternya seperti, bentuk bulat atau lonjong, panjang, berkulit mulus dan licin, dengan tangkai buah yang besar sesuai dengan ukuran buahnya.

Dewasa ini pengembangan budidaya tanaman terung merupakan salah satu andalan sayuran dataran rendah. Hampir semua provinsi di Indonesia terdapat pertanaman terung. Sentra pertanaman terung masih berpusat di pulau Jawa dan Sumatera. Lima Provinsi paling luas areal pertanaman terung adalah Provinsi Jawa Barat, Sulawesi Selatan, Bengkulu, Jawa Timur dan Jawa Tengah (Soetasad, 1996). Produksi terung di Kabupaten Lima Puluh Kota pada tahun 2013 yaitu $3.011,70$ ton dengan permintaan terung di Kabupaten Lima Puluh Kota tahun 2013 yaitu 4.656 ton.

Menurut Soetasad (1996), untuk menghasilkan buah yang berkualitas, terung lebih banyak membutuhkan pupuk Urea, TSP dan KCL, masing-masing sebanyak $150 \mathrm{~kg} / \mathrm{ha}$, $300 \mathrm{~kg} / \mathrm{ha}$ dan $150 \mathrm{~kg} / \mathrm{ha}$ atau dengan perbandingan 1:2:1. Penggunaan pupuk anorganik dalam jumlah banyak akan menimbulkan masalah bagi petani karena harga pupuk yang terus meningkat sehingga dapat meningkatkan biaya produksi terung dan akan menyebabkan penurunan pendapatan petani. Selain itu, pemakaian pupuk anorganik secara terus menerus akan menimbulkan kerusakan pada tanah. Untuk mengatasi masalah penggunaan pupuk anorganik dapat dilakukan dengan penggunaan pupuk organik, salah satunya adalah kompos bagase.

Kompos bagase adalah kompos yang berasal dari ampas tebu atau sisa penggilingan tebu. Kompos bagase merupakan bahan organik yang mempunyai prospek yang baik untuk dijadikan pupuk organik, karena mempunyai kandungan unsur hara yang tinggi. Pemberian kompos bagase dapat meningkatkan ketersediaan hara $\mathrm{N}$, P dan $\mathrm{K}$ dalam tanah, kadar bahan organik, kapasitas menahan air, serta menetralkan $\mathrm{pH}$ tanah (Ismail, 1987). Kompos bagase terdiri dari

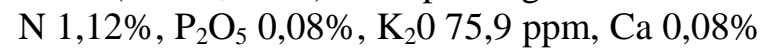
dan $\mathrm{Mg} 0,04 \%$. Sedangkan menurut Toharisman (1991), kompos bagase memiliki kadar bahan organik sekitar $90 \%$, kandungan $\mathrm{N} 0,3 \%, \mathrm{P}_{2} \mathrm{O}_{5}$ $0,02 \%, \mathrm{~K}_{2} \mathrm{O} 0,14 \%$, Ca 0,06\% dan $\mathrm{Mg}$ 0,04\%. Kompos bagase memiliki potensi yang cukup baik jika dikembangkan di Kabupaten Lima
Puluh Kota, hal ini disebabkan karena sumberdaya berupa ampas tebu cukup tersedia.

Berdasarkan masalah diatas penulis telah melakukan suatu penelitian dengan judul "Penggunaan Kompos Bagase Untuk Mengoptimalkan Produksi Tanaman Terung (Solanum melongena L.)".

\section{METODE PENELITIAN}

\section{Waktu dan Tempat}

Penelitian ini telah dilaksanakan selama 4 bulan yakni dari September sampai Desember 2015 di kebun percobaan Politeknik Pertanian Negeri Payakumbuh.

\section{Alat dan Bahan}

Alat yang digunakan yaitu cangkul, kored, garu, meteran, gembor dan ember. Bahan yang digunakan bibit terung, EM-4, ampas tebu, pupuk kandang sapi, MPPH, tali rafia, gula pasir, karung, plastik hitam, ajir, curater, NPK Mutiara dan kapur pertanian.

\section{Prosedur Penelitian}

\section{Pembuatan kompos bagase}

Metode pelaksanaan pembuatan kompos bagase adalah :

1. Bagase (ampas tebu) dicincang sebanyak $150 \mathrm{~kg} / 300 \mathrm{~m}^{2}$.

2. Pupuk kandang sapi disiapkan sebanyak 150 $\mathrm{kg} / 300 \mathrm{~m}^{2}$ sebagai stater pada pembuatan kompos bagase.

3. Pengomposan dilakukan diatas plastik hitam dengan ukuran $2 \times 2 \mathrm{~m}$.

4. Pengomposan dilakukan dengan cara membuat tumpukan ampas tebu yang sudah dicincang dengan pupuk kandang sapi, tumpukan dibuat dengan urutan ampas tebu yang sudah dicincang pada lapisan pertama kemudian pupuk kandang sapi pada lapisan kedua dan siram dengan air yang ditambahkan EM-4 dan gula pasir hingga lembab.

5. Pembuatan tumpukan dilakukan secara berulang dan berurutan sampai bahan habis dan kemudian diperoleh tumpukan dengan tinggi $0,5 \mathrm{~m}$, lebar $0,5 \mathrm{~m}$, dan panjang $1 \mathrm{~m}$.

6. Kemudian ditutup dengan rapat.

7. Pembalikan dilakukan sebanyak lima kali selama pengomposan yaitu satu kali dalam seminggu hingga pengomposan selesai selama 40 hari. 


\section{Penyiapan bibit}

Bibit yang digunakan adalah bibit yang sudah siap tanam yang dibeli dari tempat pembibitan.

\section{Pemberian kompos bagase}

Kompos bagase diberikan sebagai pupuk dasar yang diberikan setelah pengolahan lahan. Kompos bagase diberikan dengan cara membenamkan kompos dibagian tengah bedengan. Pemberian kompos bagase bertujuan untuk menyediakan unsur hara makro dan mikro yang dibutuhkan tanaman, memperbaiki struktur dan tata udara tanah sehingga memudahkan perakaran tanaman dalam menyerap unsur hara, menjadi penyangga $\mathrm{pH}$ tanah, menjadi penyangga unsur hara anorganik yang diberikan, serta membantu menjaga kelembaban tanah. Kompos bagase yang diberikan adalah kompos yang sudah matang yang telah dikomposkan selama 40 hari dengan ciri-ciri kompos telah berubah warna menjadi hitam kecoklatan, tidak berbau dan kering.

\section{Pemasangan mulsa}

Pemasangan mulsa dilakukan satu minggu setelah pemberian kompos bagase. Mulsa plastik hitam perak dipasang pada permukaan bedengan. Agar mulsa tidak mudah lepas jika terkena angin yang kencang, pada bagian tepinya disematkan bambu.

\section{Pembuatan lubang tanam}

Lubang tanam dibuat sesuai dengan jarak tanam untuk tanaman terung. Terlebih dahulu mulsa dilubangi dengan menggunakan kaleng susu yang berisi bara api. Jarak antar lubang tanaman $60 \mathrm{~cm}$ dan jarak antar barisan $70 \mathrm{~cm}$ sehingga diperoleh dua barisan dalam satu bedengan. Kedalaman lubang tanam yaitu berkisar 7-10 $\mathrm{cm}$ dan disesuaikan dengan tinggi bibit.

\section{Penanaman}

Penanaman terung dilakukan dengan jarak tanam $60 \times 70 \mathrm{~cm}$ dengan jumlah 1 bibit per lubang tanam. Setelah ditanam kemudian dilakukan penyiraman agar tanah menjadi lembab. Penanaman terung dilakukan pada sore hari saat intensitas cahaya matahari rendah.

\section{Pemasangan ajir}

Pemasangan ajir dilakukan pada umur 2 minggu setelah penanaman yang bertujuan untuk menopang batang terung agar tidak rebah ketika tertiup angin dan menopang cabang agar tidak patah ketika sudah berbuah. Tinggi ajir yang digunakan yaitu $1 \mathrm{~m}$ dengan kebutuhan ajir pada luasan lahan $300 \mathrm{~m}^{2}$ yaitu 505 batang. Pemeliharaan, meliputi kegiatan penyiraman, penyiangan, pemupukan dan pengendlian hama penyakit.

\section{Panen dan penanganan pascapanen}

\section{a. Panen}

Panen terung mulai dilakukan pada umur 2,5 bulan setelah tanam dan panen dilakukan sebanyak 13 kali. Panen dilakukan pada pagi atau sore hari saat intensitas cahaya matahari rendah agar tidak merusak kualitas buah terung. Panen terung dilakukan dengan cara di petik, pemetikan dilakukan dengan hati-hati agar tidak merusak cabang tempat pemetikan buah serta untuk menjaga agar bunga tidak berguguran. Buah terung dipanen dengan bantuan gunting atau dengan pisau yang bersih dan tajam agar bekas pemotongannya halus.

\section{b. Penanganan pascapanen}

Penanganan pascapanen terung yang dilakukan yaitu sortasi, pembersihan dan pengemasan. Sortasi yaitu melakukan pemilihan berdasarkan kualitas terung, misalnya dipisahkan dari buah yang rusak, busuk atau cacat. Kemudian dilakukan pula pembersihan, pembersihan dilakukan dengan cara membuang kotoran dan bagian buah terung yang tidak diinginkan. Setelah dilakukan sortasi dan pembersihan kemudian buah terung dikemas atau di masukkan ke dalam wadah berupa karung dan kemudian untuk dijual.

\section{Pemasaran}

Pemasaran produksi terung dilakukan dengan dua cara yaitu dipasarkan dengan cara langsung kepada konsumen di daerah Tanjung Pati dan sekitarnya dan dijual kepada distributor. 


\section{HASIL DAN PEMBAHASAN}

\section{Hasil}

Tabel 1. Rekapitulasi Perbandingan Biaya Perencanaan dengan Realisasi Pada Budidaya Tanaman Terung Untuk Luasan Lahan $300 \mathrm{~m}^{2}$

\begin{tabular}{|c|c|c|c|c|}
\hline No. & Parameter & Rencana & Realisasi & Selisih \\
\hline 1 & Biaya alat $(\mathrm{Rp})$ & 22.833 & 22.833 & 0 \\
\hline 2 & Biaya bahan (Rp) & 689.750 & 482.300 & 207.450 \\
\hline 3 & Tenaga kerja (Rp) & 365.000 & 343.000 & 22.000 \\
\hline 4 & Sewa lahan (Rp) & 20.000 & 20.000 & 0 \\
\hline 5 & Biaya bunga modal (Rp) & 53.307 & 43.407 & 9.900 \\
\hline 6 & Biaya total lain-lain (Rp) & 126.614 & 106.814 & 19.800 \\
\hline 7 & Produksi (kg) & 342,78 & 575 & $-232,22$ \\
\hline 8 & Proyeksi laba rugi (Rp) & 198.301 & 835.310 & -637.009 \\
\hline 9 & Pendapatan (Rp) & 1.371 .120 & 1.746 .850 & -375.730 \\
\hline 10 & Profitabilitas (\%) & 16,9 & 92 & $-75,1$ \\
\hline 11 & RC Ratio & 1,17 & 1,92 & $-0,75$ \\
\hline 12 & BEP harga (Rp) & 3.421 & 1.585 & 1.836 \\
\hline 13 & BEP hasil (kg) & 293,2 & 300 & $-6,8$ \\
\hline 14 & BEP lahan $\left(\mathrm{m}^{2}\right)$ & 256,61 & 156,55 & 100,06 \\
\hline
\end{tabular}

\section{Pembahasan}

\section{Aspek produksi}

Produksi terung pada proyek usaha mandiri dengan perlakuan penggunaan kompos bagase yaitu $575 \mathrm{~kg} / 300 \mathrm{~m}^{2}$ atau 19,2 Ton/Ha. Hal ini menunjukkan bahwa produksi terung sudah cukup tinggi jika dibandingkan dengan produksi terung di Kabupaten Lima Puluh Kota pada Tahun 2013 yaitu 11,426 Ton/Ha atau $342,78 \mathrm{~kg} / 300 \mathrm{~m}^{2}$ (Badan Pusat Statistik Kabupaten Lima Puluh Kota, 2014).

\section{Aspek finansial}

Proyek usaha mandiri budidaya terung dengan menggunakan kompos bagase memiliki perbandingan biaya antara rencana dengan realisasi. Biaya bahan pada rencana yaitu $\mathrm{Rp}$ 658.875 sedangkan pada realisasi hanya $\mathrm{Rp}$ 482.300 atau dengan selisih antara rencana dan reaslisasi yaitu $\mathrm{Rp}$ 207.450. Hal ini disebabkan karena beberapa bahan yang digunakan dalam realisasi tidak sebesar yang direncanakan pada proposal, seperti halnya pada rencana kebutuhan MPPH yang digunakan yaitu $1 \mathrm{Bal}$ dengan harga $\mathrm{Rp} 280.000$ namun pada realisasi yang digunakan hanya $1 / 4 \mathrm{Bal}$ untuk luasan lahan $300 \mathrm{~m}^{2}$ dengan total biaya yang dibutuhkan hanya Rp 120.000 sehingga terjadi selisih sebesar Rp 160.000. Selain itu, biaya ajir terjadi selisih sebesar Rp 50.500 karena harga ajir yang direncanakan adalah Rp 250 dengan jumlah ajir 505 batang dengan total biaya $\mathrm{Rp}$ 126.250, namun pada realisasi harga ajir hanya Rp 150 dengan kebutuhan 505 batang dan total biaya ajir dalam realisasi yaitu $\mathrm{Rp} 75.750$. Disamping itu, masih ada beberapa bahan yang terjadi selisih antara rencana dan realisasi seperti yang sudah tetera pada Tabel 8 .

Total biaya rencana kebutuhan tenaga kerja yaitu $R p 365.000$ dan pada realisasi hanya $R p$ 343.000 atau dengan selisih antara rencana dan realisasi sebesar Rp 22.000, hal ini disebabkan karena waktu yang digunakan pada realisasi budidaya terung lebih sedikit dibandingkan dengan rencana atau dengan selisih waktu keseluruhan kurang lebih 3 jam yaitu 7,3 HKO pada rencana dan 6,86 HKO pada realisasi.

Pada biaya alat tidak terjadi selsih antara rencana dan realisasi karena alat yang digunakan pada realisasi. Alat yang di rencanakan pada kebutuhan alat.

Produksi terung dengan menggunakan kompos bagase pada proyek usaha mandiri mencapai $575 \mathrm{~kg} / 300 \mathrm{~m}^{2}$ atau sekitar 19,2 Ton/Ha dengan harga jual rata-rata yaitu $\mathrm{Rp}$ 3.038, sehingga diperoleh pendapatan sebesar $\mathrm{Rp}$ 1.746.850. Total biaya yang di keluarkan dalam budidaya terung yaitu Rp 911.540. 
Keuntungan yang diperoleh $\mathrm{Rp}$ 835.310, profitabilitas $92 \%$ atau $>15 \%$ yang menyatakan bahwa proyek usaha mandiri budidaya terung menggunakan kompos bagase layak diusahakan. RC Ratio sebesar 1,92 atau > 1 yang menyatakan bahwa proyek usaha mandiri budidaya terung dengan menggunakan kompos bagase untung.

Keuntungan proyek usaha mandiri pada realisasi lebih tinggi dibandingkan dengan rencana walaupun dengan harga yang lebih rendah dibandingkan dengan yang direncanakan yaitu Rp 4.000 dan pada realisasi harga jual

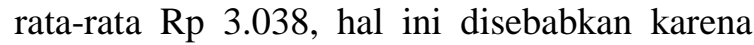
produksi terung pada realisasi lebih tinggi yaitu $575 \mathrm{Kg}$ dibandingkan dengan rencana yaitu $342,78 \mathrm{~kg}$ atau dengan selisih sekitar -232,22 $\mathrm{kg}$.

\section{Aspek teknis}

Proyek usaha mandiri dengan judul "Penggunaan Kompos Bagase Untuk Mengoptimalkan Produksi Tanaman Terung (Solanum melongena L.)" telah dilaksanakan selama 4 bulan yakni dari bulan SeptemberDesember 2015. Tahap budidaya yang dilakukan pertama kali pada proyek usaha mandiri yaitu pembuatan kompos bagase. Kompos bagase dibuat dengan menggunakan stater pupuk kandang sapi dengan waktu pengomposan selama 40 hari. Kompos bagase yang dibuat dijadikan sebagai pupuk dasar pada budidaya dengan syarat kompos bagase yang diaplikasikan ke lahan adalah kompos bagase yang sudah matang dengan ciri-ciri sudah berubah warna menjadi hitam kecoklatan, tidak berbau dan kering.

Tahap kedua yaitu pengolahan lahan, pada realisasi luas lahan yaitu $300 \mathrm{~m}^{2}$ dan dilahan sudah terdapat 3 buah bedengan sehingga dalam realisasi tidak dilakukan kegiatan pembuatan bedengan. Bedengan yang sudah ada dilahan harus dibersihkan dan digemburkan terlebih dahulu, karena bedengan tersebut merupakan lahan bekas tempat pembibitan sawit yang kemudian ditanami jagung sehingga tekstur tanah menjadi keras dan kering, miskin unsur hara serta terdapat banyak sisa-sisa tanaman jagung. Setelah diolah, bedengan tersebut diberi kapur dengan tujuan menetralkan $\mathrm{pH}$ tanah agar sesuai dengan syarat tumbuh terung dengan $\mathrm{pH}$ 5,0-6,0 (Soetasad dan Muryanti 1999). Kapur juga berfungsi memperbaiki struktur, tekstur dan agregat tanah agar baik bagi pertumbuhan tanaman. Setelah pengapuran kemudian kompos bagase diaplikasikan kelahan dengan cara menebarkan secara rata pada bagian tengah bedengan dan kemudian ditimbun. Bedengan yang sudah diolah, dikapur dan telah diberikan kompos bagase kemudian dilakukan pemasangan MPPH dengan tujuan menekan pertumbuhan gulma dan menjaga kelembaban tanah.

Bibit yang digunakan dalam proyek usaha mandiri adalah terung ungu yang dibeli dari tempat pembibitan. Bibit terung yang digunakan adalah bibit terung yang sudah berumur 2-4 minggu, yang sudah memiliki 4-5 helai daun, tidak terserang hama dan penyakit, serta pertumbuhannya seragam. Kemudian buat lubang tanam dan tanam bibit 1 per lubang tanam.

Pemeliharaan yang dilakukan dalam budidaya antara lain penyulaman dengan tujuan mengganti tanaman yang pertumbuhannya tidak normal atau telah mati. Penyiraman dilakukan setiap hari terutama dimusim awal tanam pada bulan Oktober, karena curah hujan yang kurang dan kondisi alam yang tidak baik akibat adanya kabut asap yang cukup tebal sehingga perlu dilakukan penyiraman setiap hari agar dapat memenuhi kebutuhan air tanaman. Tanaman yang sudah berumur dua minggu kemudian diberi ajir dan batang diikat dengan tali agar tanaman tidak patah apabila sudah berbuah atau tertiup angin kencang. Pada budidaya juga dilakukan pengendalian hama dan penyakit yang secara umum dilakukan secara manual atau mekanis.

Pemeliharaan lainnya yaitu pemupukan, pemupukan dilakukan dengan menggunakan pupuk anorganik seperti Urea dan NPK Mutiara untuk menambah ketersediaan unsur hara yang dibutuhkan tanaman. Namun, dalam proyek usaha mandiri dengan menggunakan teknologi kompos bagase dapat mengefisiensi penggunaan pupuk anorganik. Kompos bagase mengandung kadar bahan organik yang tinggi yang baik untuk tanaman serta dapat memperbaiki sifat fisika, kimia dan biologi tanah. Berdasarkan manfaat-manfaat kompos bagase tersebut dapat dilakukan efisiensi pupuk hingga $50 \%$ dari dosis standar. Penggunaan kompos bagase merupakan suatu sistem dalam menerapkan sistem pertanian berwawasan lingkungan karena kompos bagase dibuat dari bahan organik yang tidak memiliki residu. Hal ini menunjukkan bahwa kompos bagase memiliki pengaruh yang baik dalam budidaya tanaman terung untuk mengoptimalkan produksi terung. 
Pemanenan terung mulai dilakukan pada umur 2,5 bulan setelah tanam, setelah pemanenan dilakukan sortasi yaitu pemilihan produksi berdasarkan kualitas. Pemasaran terung dilakukan dengan dua cara yaitu penjualan secara langsung ke konsumen dan dijual kepada distributor. Selama pemasaran terjadi fluktuasi harga (lampiran 3). Harga terung dipasar terjadi penurunan karena permintaan sedikit sementara jumlah produk terung dipasar banyak. Selain itu, Fluktuasi harga juga disebabkan karena adanya persaingan dengan komoditi lain dipasar seperti petai dan jengkol (Wawancara dengan Distributor di Kabupaten Lima Puluh Kota, 2015).

\section{KESIMPULAN DAN SARAN}

\section{Kesimpulan}

1. Penggunaan kompos bagase dapat mengoptimalkan produksi tanaman terung dan mengurangi penggunaan pupuk kimia.

2. Produksi tanaman terung pada proyek usaha mandiri ini yaitu $575 \mathrm{~kg} / 300 \mathrm{~m}^{2}$ atau 19,2 Ton/Ha.

3. Dengan penggunaan kompos bagase dapat menerapkan sistem pertanian berwawasan lingkungan karena kompos bagase dibuat dari bahan organik sehingga tidak memiliki residu.

4. Proyek usaha mandiri mendapatkan keuntungan $\mathrm{Rp}$ 835.310, profitabilitas $92 \%$ yang artinya > $15 \%$ proyek layak diusahakan dan RC Ratio sebesar 1,92 yang artinya $>1 \%$ proyek dinyatakan untung.

\section{Saran}

Berdasarkan kesimpulan diatas pada budidaya tanaman terung disarankan menggunakan kompos bagase karena dapat mengoptimalkan produksi tanaman terung.

\section{DAFTAR PUSTAKA}

Agatha, P. 2013. Budidaya dan manfaat terung. http://kinagatha.blogspot.com201303mak alah-budidaya-dan-manfaat-terung.html. Diakses pada 11 April 2015, 01:08.

Anonim. 2012. Jenisjenis kompos. httpagristark.blogspot.com 201203jenis-jenis-kompos.html. Diakses pada 27 April 2015, 12:35.

Anonim. 2013. Pembuatan pupuk organik (kom pos). http://karangtarunamorowudiwetan. blogspot.com201309pembuatan-pupuk- organik-kompos.html. Diakses pada 18 April 2015, 03:18.

Badan Penelitian dan Pengembangan PT. Gula Putih Mataram. 2002. Hasil analisa bagase, blotong dan abu. PT. Gula Putih Mataram. Lampung.

Badan Pusat Statistik, 2014. Kabupaten Lima Puluh Kota. Dalam Angka. BPS Kabupaten Lima Puluh Kota.

Budiman, E. 2008. Cara \& upaya budidaya terung. CV. Wahana IPTEK Banadung. 124 Halaman.

Gaur, D. C. 1980. Present status of composting and agricultural aspect. In : Hesse, P.R. (ed). Improving Soil Fertility Trough Organic Recycling, Compost Technology. FAO of united Nation. New Delhi. P. 1-6.

Ismail, I. 1987. Peranan "Bioearth" terhadap status hara makro, sifat-sifat tanah, pertumbuhan dan bobot kering tanaman tebu pada berbagai ketebalan tanah lapisan atas. Bulletin (1): 1-7.

Isroi. 2007. Pengomposan limbah kakao. Http:// isroi.files.wordpress.com/2008/02/kompo slimbahkakao. pdf. 18 April 2015. 15:00.

Mulyadi A., Mustamir E., dan Maryandi A. 2013. Pengaruh kompos base terhadap pertumbuhan dan hasil tanaman kailan pada tanah alluvial. http://jurnal.untan.ac. idindex.phpjspparticleview3343. Diakses pada 16 April 2015, 02:15.

Riyanto, S. 1995. Perbaikan produktivitas tanah dan tanaman tebu melalui pemanfaatan kompos casting. Makalah dalam Kongres HITI di Jakarta, tanggal 12-15 Desember 1995.

Saputra, A. 2012. Pengertian kompos menurut $p$ ara ahli. http://fourseasonnews.blogspot.c om201301pengertian-kompos-menurutpara-ahli.html. Diakses pada 27 April 2015, 07:20.

Sarwono, Purwono, dan Guntoro D. 2003. Pengaruh pemberian kompos bagase terhadap serapan hara dan pertumbuhan $\mathrm{t}$ anaman tebu (Saccharum officinarum). $\mathrm{H}$ ttp://journal.Ipb.Ac.Idindex.Phpjurnalagr onomiarticledownload1481562. Diakses pada 27 April 2015, 12:46.

Soetasad, A. A. dan S. Muryanti. 1996. Budidaya terung lokal dan terung jepang. Penebar Swadaya. Jakarta. 90 Halaman. 
Toharisman, A. 1991. Potensi dan pemanfaatan limbah industri gula sebagai sumber bahan organik tanah. Berita (4): 66-69. 